\title{
Editor's Introduction: BCA takes hold in the U.S. Federal Government
}

It is important to understand the roots of our discipline. We are honored to be able to publish the following invited essay, "How Systems Analysis, Cost-Effectiveness Analysis or Benefit-Cost Analysis first became influential in Federal Government Program Decision-Making” by Alain Enthoven (2019) of Stanford University, who helps us understand the beginning and growth of benefit-cost analysis (BCA) in the United States government. Alain began at the Rand Corporation and was one of the so-called "whiz kids" that participated in applying the principles of cost-effectiveness in government decisions in the Department of Defense and the increasing importance of BCA principles via the planning programming budgeting system (PPBS). Thank you Alain for what you have done to advance our discipline and its importance in policymaking.

Thomas J. Kniesner

Editor, Journal of Benefit-Cost Analysis

\section{Reference}

Enthoven, Alain. 2019. "How Systems Analysis, Cost-Effectiveness Analysis, or Benefit-Cost Analysis First Became Influential in Federal Government Program Decision-Making." Journal of Benefit-Cost Analysis 10(2): 146-155. 